\title{
Syntheses and Characterizations of Allyl Cellulose and Glycidyl Cellulose
}

\author{
MU-SHIH LIN* and CHUNG-SONG HUANG \\ Department of Applied Chemistry, National Chiao-Tung University, Hsinchu, Taiwan 30050, China
}

\begin{abstract}
SYNOPSIS
Allyl cellulose was synthesized by reacting cellulose with allyl bromide in homogeneous $\mathrm{LiCl} / \mathrm{DMAc}$ solution containing $\mathrm{NaOH}$ powder. The degree of substitution (DS) per anhydroglucose (AHG) unit was determined by titrating the allyl cellulose with bromine in chloroform solution, and an allyl DS of 2.80 was found. Glycidyl cellulose was then prepared by reacting this allyl cellulose with peracetic acid in methylene chloride at ambient temperature for 6 days. The measured reaction rate constant was $1.33 \times 10^{-3} \mathrm{~min}^{-1}$. The glycidyl cellulose thus obtained with a glycidyl DS of 2.58 was determined by titrating the product with perchloric acid in conjunction with tetrabutylammonium iodide. The 2.58 of glycidyl DS was also confirmed by ${ }^{1} \mathrm{H}-\mathrm{NMR}$ integration. Both allyl cellulose and glycidyl cellulose were analyzed and characterized with FTIR, ${ }^{1} \mathrm{H}-\mathrm{NMR},{ }^{13} \mathrm{C}-\mathrm{NMR}$, TGA, and GPC. During epoxidation of allyl cellulose, possible side reaction leading to ester formation was evidenced from the continuous increase of $\nu_{\mathrm{C}=0}$ at $1735 \mathrm{~cm}^{-1}$ in FTIR analyses. In addition, a bimodal distribution and a decreased molecular weight for glycidyl cellulose were found from GPC data, which might suggest a possible chain scission at the cellulosic ether linkage. (C) 1992 John Wiley \& Sons, Inc.
\end{abstract}

Keywords: crosslinkable $\bullet$ allylation $\bullet$ epoxidation $\bullet{ }^{1} \mathrm{H}$-NMR integration $\bullet$ degree of substitution (DS) • anhydroglucose (AHG) unit

\section{INTRODUCTION}

Cellulose is one of the most abundant of naturally occurring polymers. Cellulose itself and its derivatives are also of great industrial importance. However, the regularity of cellulose chain and extensive inter- and intramolecular $\mathrm{H}$-bonding between hydroxy groups cause cellulose to be a tightly-packed crystalline material. As a result, it is insoluble, even in the $\mathrm{H}$-bonding solvents. Although cellulose is a linear polymer, it is infusible, and decomposition occurs before a sufficient number of hydrogen bonds are broken. ${ }^{1}$ Thus, cellulose can not be processed either in melt or in solution. Despite this difficulty, several cellulose derivatives with less $\mathrm{H}$-bonding have been developed which are processable and are of commercial interest. Most of these cellulose derivatives are chemically modified from the original

* To whom all correspondence should be addressed.

Journal of Polymer Science: Part A: Polymer Chemistry, Vol. 30, 2303-2312 (1992) (C) 1992 John Wiley \& Sons, Inc. CCC 0887-624X/92/112303-10\$04.00 cellulose in heterogeneous reaction mixtures. However, such reactions are normally difficult to control. In 1979 the dissolution of cellulose in $N, N$-dimethylacetamide (DMAc) and lithium chloride $(\mathrm{LiCl})$ was first reported by McCormick and his co-workers. ${ }^{2-4}$ Since then several solvent mixtures for cellulose have been disclosed and reviewed. ${ }^{5,6}$ In recent years, a number of cellulose derivatives were prepared in $\mathrm{LiCl} / \mathrm{DMAc}$ solution. ${ }^{1,6-9}$ In this article, we would like to report two soluble and crosslinkable cellulose derivatives with high degrees of substitutions, i.e., allyl cellulose and glycidyl cellulose, which were synthesized in homogeneous solutions.

\section{EXPERIMENTAL}

\section{Materials}

\section{Starting Materials}

Cellulose (microcrystalline) and allyl bromide were purchased from Merck Co. Peracetic acid was ob- 
Table I. Comparison of Molecular Weights and Molecular Weight Distributions for Allyl Cellulose and Glycidyl Cellulose by GPC

\begin{tabular}{lccc}
\hline \multicolumn{1}{c}{ Sample } & $\bar{M}_{n} \times 10^{-4}$ & $\bar{M}_{w} \times 10^{-4}$ & $\bar{M}_{w} / \bar{M}_{n}$ \\
\hline Allyl cellulose & 2.74 & 12.58 & 4.59 \\
Glycidyl cellulose & 1.30 & 2.65 & 2.04 \\
\hline
\end{tabular}

tained from Aldrich Co. Cellulose and peracetic acid were used without further purification. Allyl bromide was purified by distillation under reduced pressure.

Analytical grade reagents, crystal violet $\left(\mathrm{C}_{25} \mathrm{H}_{30} \mathrm{ClNa}\right)$, tetrabutylammonium iodide, and perchloric acid were obtained from Merck Co. and were used without further purification.

\section{Instruments}

FTIR spectra were obtained by using a Nicolet model 520 with a resolution of $1 \mathrm{~cm}^{-1}$. Samples were cast on $\mathrm{KBr}$ plates from $\mathrm{CHCl}_{3}$ solutions and were sandwiched.

${ }^{1} \mathrm{H}-\mathrm{NMR}$ spectra were recorded with a Varian Gemini model $300 .{ }^{13} \mathrm{C}-\mathrm{NMR}$ spectra were obtained with a Bruker MSC model 200 using $54.7^{\circ}$ of magic angle spinning at $3500 \mathrm{rpm}$. TMS was used as internal standard for both ${ }^{1} \mathrm{H}$ - and ${ }^{13} \mathrm{C}-\mathrm{NMR}$ spectra.

TGA thermgrams were recorded with a Seiko
Model 100 instrument at a heating rate of $10^{\circ} \mathrm{C} /$ min and in nitrogen atmosphere.

\section{Synthesis of Allyl Cellulose}

Cellulose $(10 \mathrm{~g})$ in $\mathrm{LiCl} / \mathrm{DMAC}(6 \%, 300 \mathrm{~mL})$ was charged into a four-necked flask equipped with a nitrogen inlet and outlet. The mixture was heated to $80^{\circ} \mathrm{C}$ under nitrogen atmosphere with constant stirring for $1.5 \mathrm{~h}$ until the cellulose was completely dissolved. At this time the color of the solution became golden yellow. The solution was then cooled in an ice bath to $0^{\circ} \mathrm{C}$, followed by addition of $\mathrm{NaOH}$ powder $(74 \mathrm{~g})$. Then, allyl bromide $(157 \mathrm{~mL}, 1.814$ $\mathrm{mol}$ ) was added dropwise. The reaction mixture was heated to $80^{\circ} \mathrm{C}$ and kept at this temperature for 5 $\mathrm{h}$ to complete the reaction. Water was added and the lower layer was extracted with chloroform. After evaporation of chloroform, a syrup was obtained. This syrup was washed with distilled water and filtered, a white powder of allyl cellulose with an allyl DS of 2.80 and a yield of $81.7 \%$ was obtained. Allyl cellulose was kept in nitrogen atmosphere in refrigerator for further use.

\section{Synthesis of Glycidyl Cellulose}

Methylene chloride ( $300 \mathrm{~mL}$ ), sodium acetate ( 3.75 $\mathrm{g}$ ), and the above allyl cellulose ( 2.80 of DS, $3 \mathrm{~g}$ )

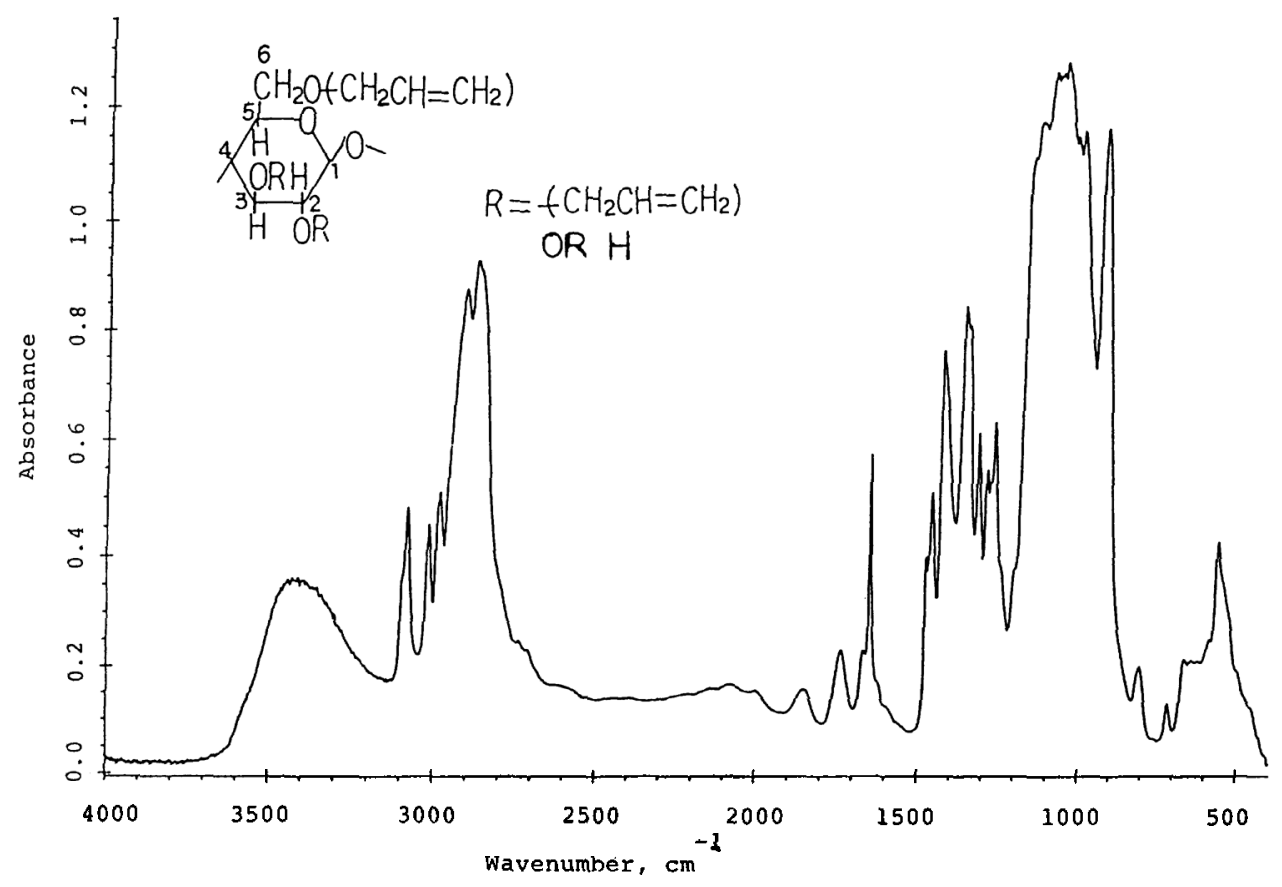

Figure 1. FTIR spectrum of allyl cellulose. 

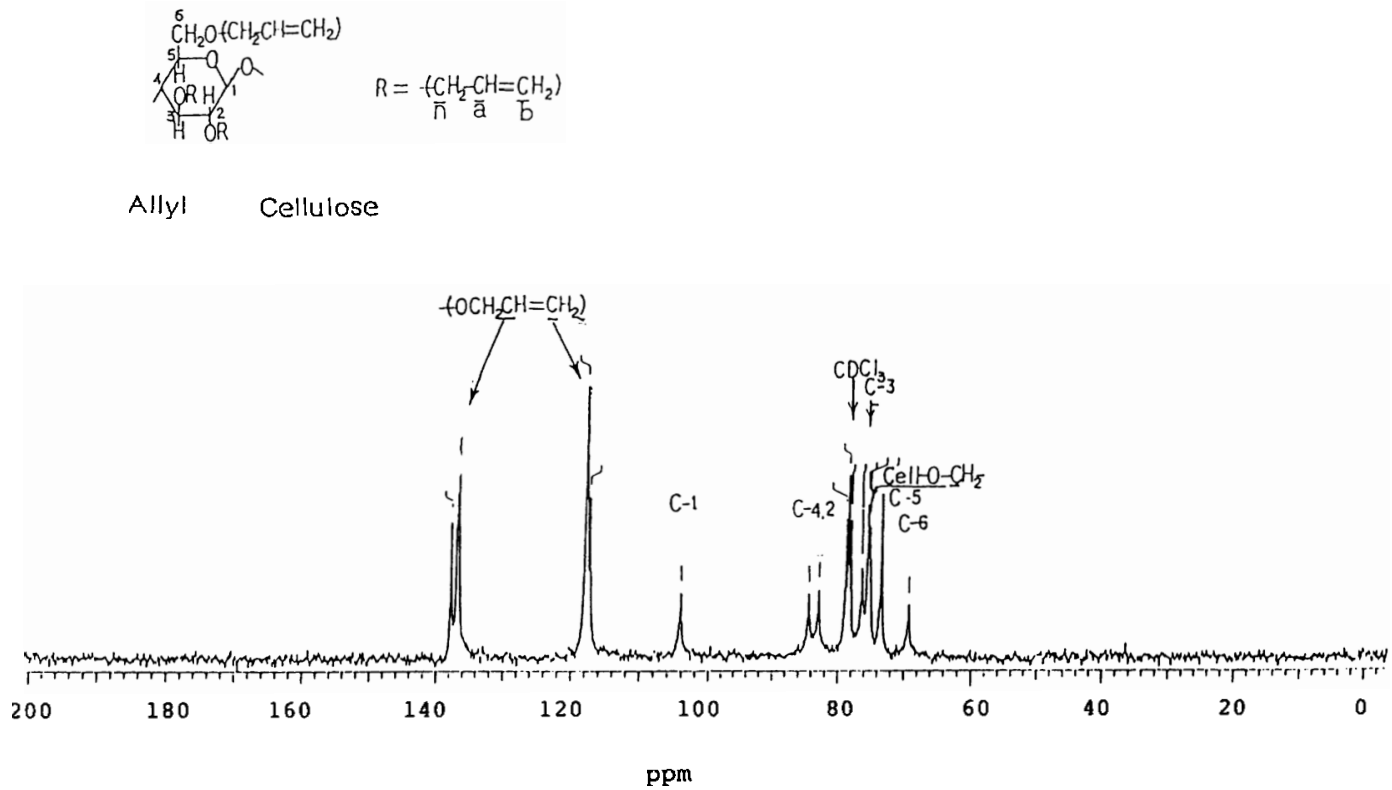

Figure 2. ${ }^{13} \mathrm{C}-\mathrm{NMR}$ spectrum of allyl cellulose.

were charged into a $500 \mathrm{~mL}$ three-necked flask equipped with a nitrogen inlet and outlet, and a mechanical stirrer. After the mixture became homogeneous, $64.5 \mathrm{~g}$ of peracetic acid/HOAc solution $(32 \%)$ was added gradually. The reaction mixture was stirred constantly at room temperature for 6 days. At the end of reaction, distilled water (500 $\mathrm{mL}$ ) was added. The lower methylene chloride layer was treated with $\mathrm{NaHCO}_{3}$ solution (10\%), and washed with water several times until it became neutral. After evaporation of methylene chloride, a white powder of glycidyl cellulose with a glycidyl DS of 2.58 and a yield of $95.7 \%$ was obtained.

\section{The Allyl Degree of Substitution (DS)}

Allyl cellulose $(0.200 \mathrm{~g})$ was dissolved in $10 \mathrm{~mL}$ of $\mathrm{CH}_{2} \mathrm{Cl}_{2}$, and titrated with bromine solution $(2.9630$

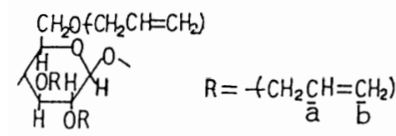

Allyl Cellulose

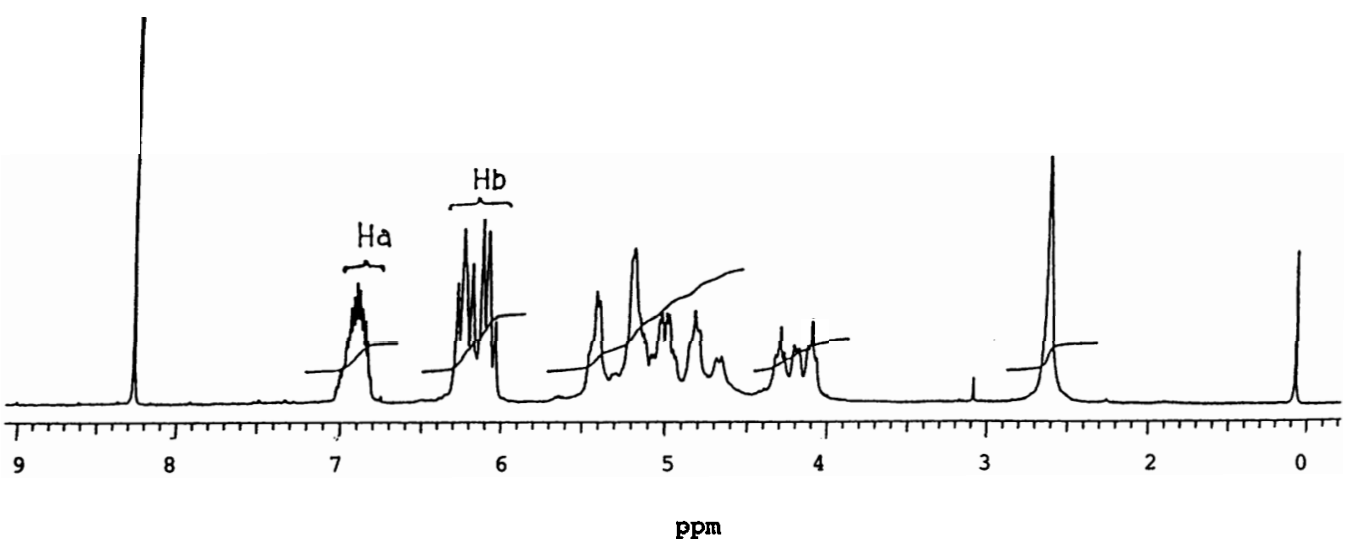

Figure 3. ${ }^{1} \mathrm{H}-\mathrm{NMR}$ spectrum of allyl cellulose. 


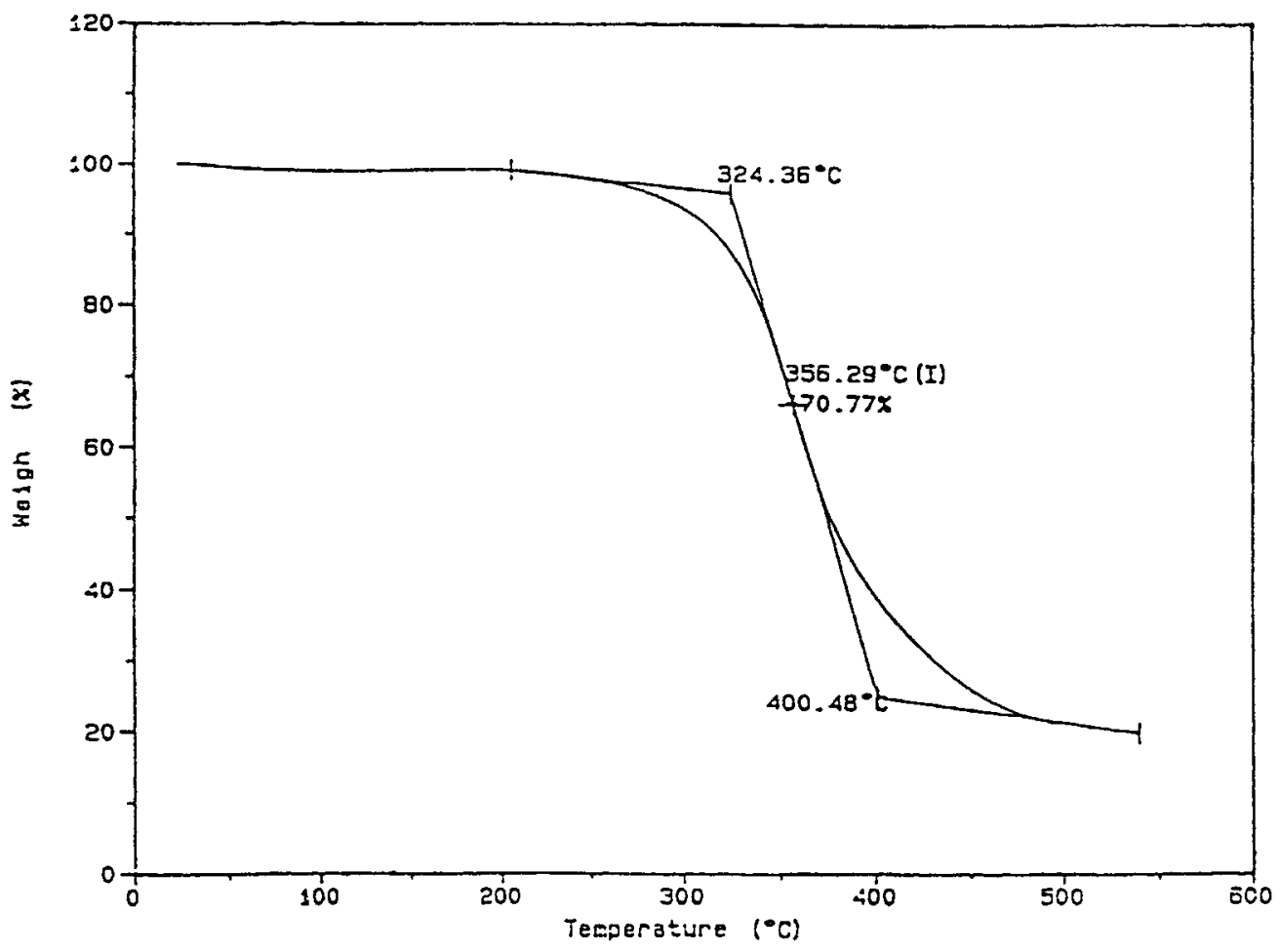

Figure 4. TGA thermogram of allyl cellulose.

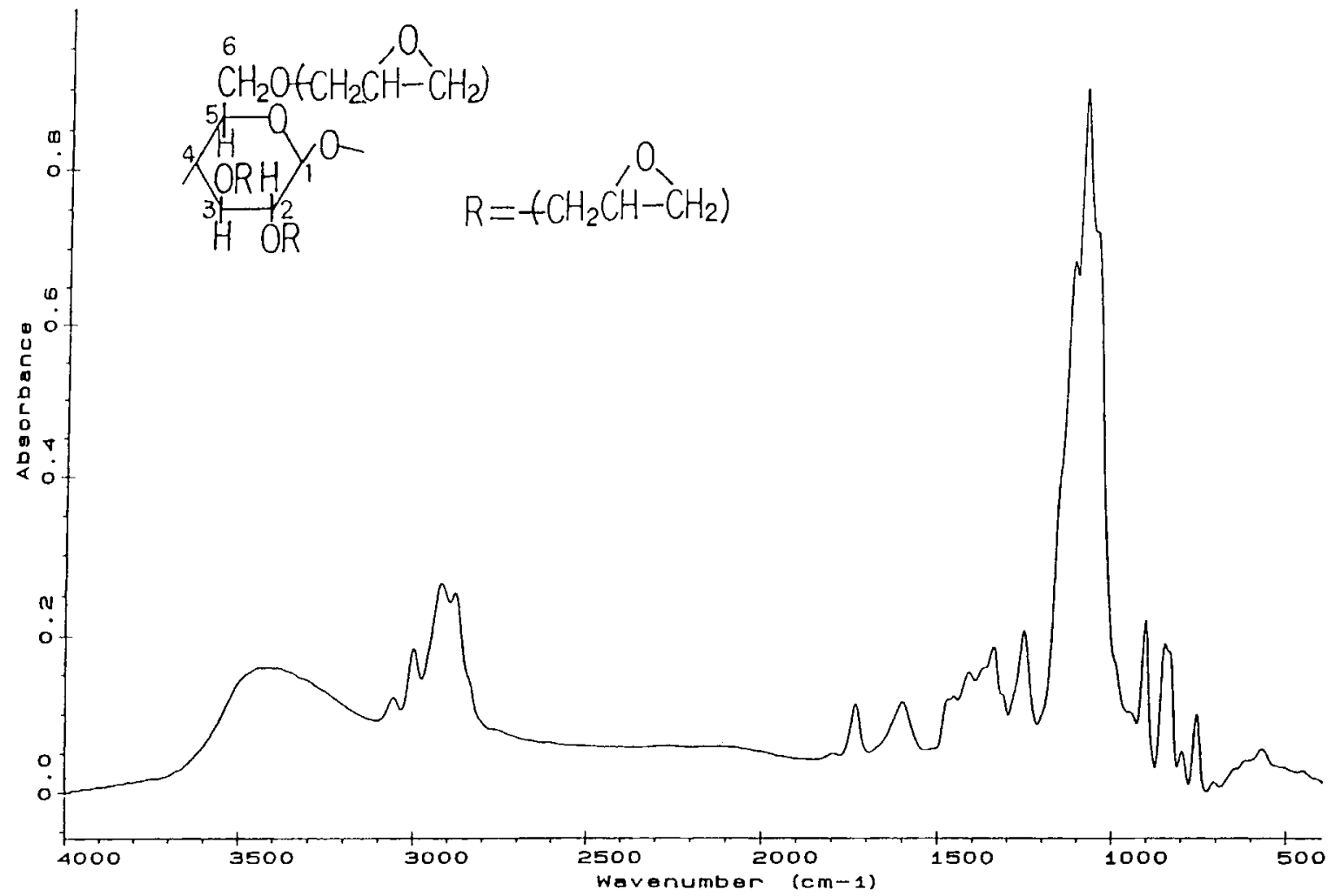

Figure 5. FTIR spectrum of glycidyl cellulose. 


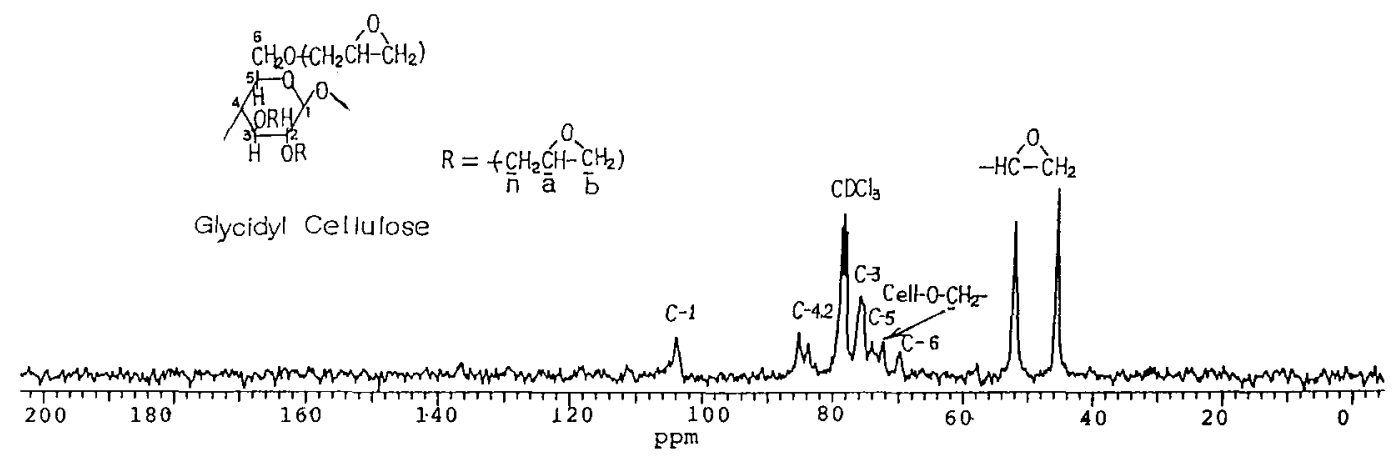

Figure 6. ${ }^{13} \mathrm{C}-\mathrm{NMR}$ spectrum of glycidyl cellulose.

$\mathrm{g}$ of bromine in $250 \mathrm{~mL}$ of $\mathrm{CH}_{2} \mathrm{Cl}_{2}$ ). The end point was taken when the bromine color persisted. The allyl DS per AHG unit was calculated by eq. (1):

$$
\mathrm{DS} \times\left(\frac{W_{1} \times(1-a)}{159+(3-\mathrm{DS})+41 \times \mathrm{DS}}\right)=\frac{W_{2}}{159.8}
$$

where $W_{1}$ is the weight of allyl cellulose, and $a$ is the fraction of solvent contained in allyl cellulose which can be obtained from TGA thermogram. The molecular weight of allyl cellulose per AHG unit is $[159+(3-D S)+41 \times D S] . W_{2}$ is the precise weight of the bromine consumed in the titration.

\section{The Epoxide Equivalent Weight (EEW) and the Glycidyl Degree of Substitution (DS)}

Glycidyl cellulose $(0.100 \mathrm{~g})$ was dissolved in chloroform $(15 \mathrm{~mL})$ and $10 \mathrm{~mL}$ of tetrabutylammonium iodide was added. Two drops of crystal violet was added as indicator. The mixture was titrated with $0.1 \mathrm{~N} \mathrm{HClO}_{4}$ to the end point (permanent greenish color). The glycidyl DS was calculated by eq. (2), while epoxide equivalent weight (EEW) was calculated by eq. (3):

$$
\left(\frac{W(1-b)}{274+16 \times \mathrm{DS}}\right) \times \mathrm{DS}=N V \times 10^{-3}
$$

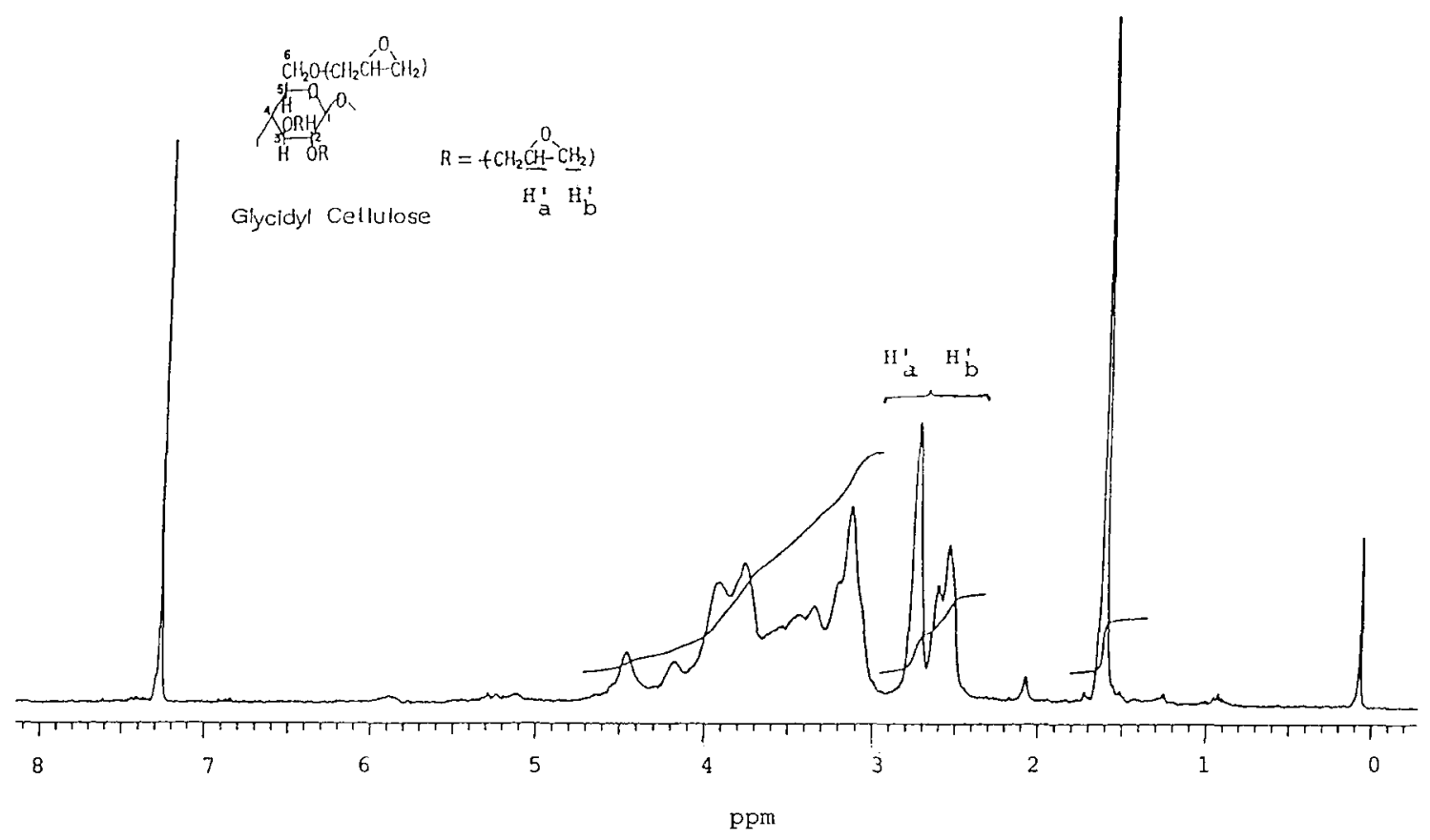

Figure 7. ${ }^{1} \mathrm{H}$ NMR spectrum of glycidyl cellulose. 

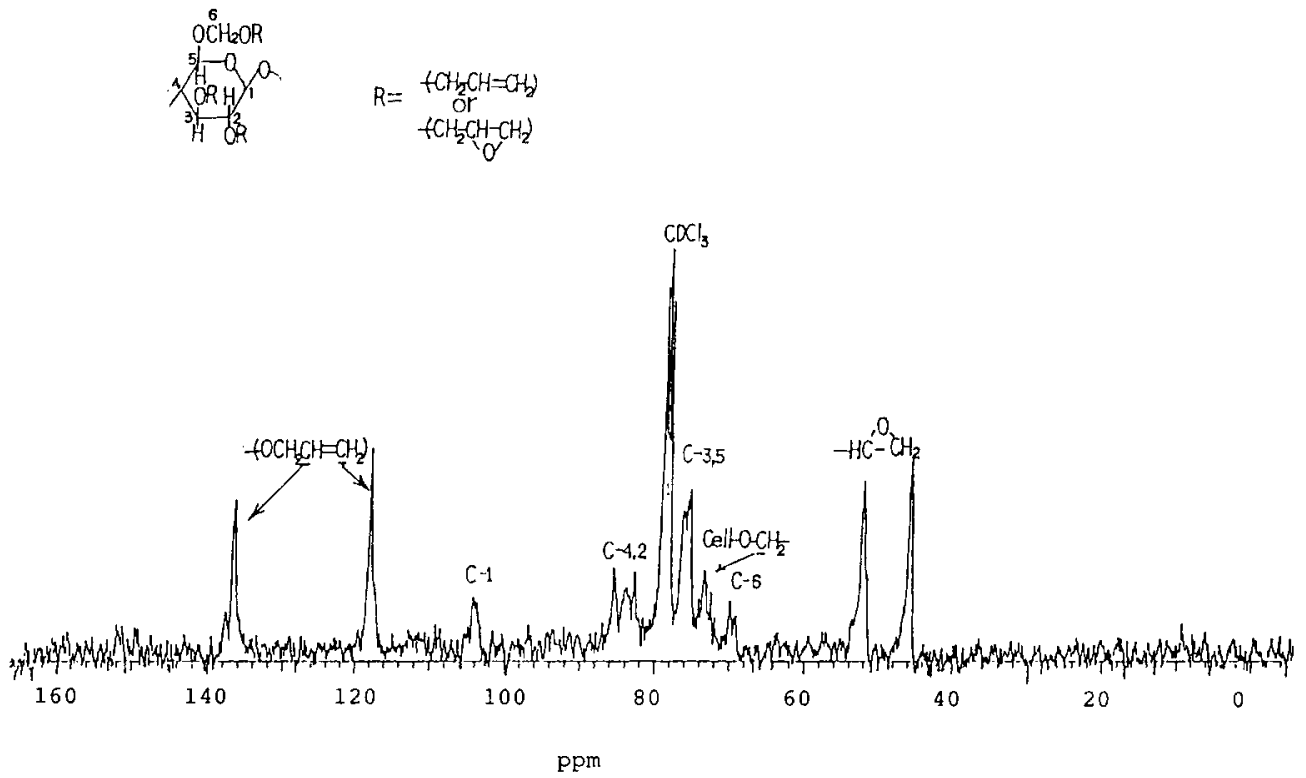

Figure 8. ${ }^{13} \mathrm{C}-\mathrm{NMR}$ spectrum of a partially epoxidized allyl cellulose.

$$
\mathrm{EEW}=\frac{1000 W(1-b)}{\left(V-V_{0}\right) N}
$$

where $W$ is the weight (in grams) of glycidyl cellulose, $b$ is the fraction of solvent contained in glycidyl cellulose which was obtained directly from TGA thermogram, $(274+16 \times \mathrm{DS})$ is the molecular weight of glycidyl cellulose per AHG unit, $N$ is the concentration of $\mathrm{HClO}_{4}$ in normality, and $V$ and $V_{0}$ are volumes (in milliliters) of $\mathrm{HClO}_{4}$ consumed in the titration and in the blank titration, respectively.

\section{RESULTS AND DISCUSSIONS}

When cellulose dissolved in the $\mathrm{LiCl} / \mathrm{DMAC}$ mixture, a golden homogeneous solution was obtained. McCormick and co-workers reported that the reactivity of cellulose hydroxy groups in $\mathrm{S}_{N} 2$ reaction in $\mathrm{LiCl} / \mathrm{DMAc}$ is insufficient to result in reasonable yield and, addition of $\mathrm{NaOH}$ powder results in the more reactive cellulose alkoxide anion. ${ }^{7}$ Although $\mathrm{NaOH}$ was not soluble in $\mathrm{LiCl} / \mathrm{DMAc}$, the fine $\mathrm{NaOH}$ powder was well suspended in cellulose solution, and the reaction mixture was somewhat slurry in nature. The allylation of cellulose alkoxide with allyl bromide proceeded smoothly and resulted in a product with a high allyl DS of 2.80 per $A H G$ unit. The allyl DS was analyzed by titration with bromine. McCormick et al. also reported that addition of $\mathrm{NaOH}$ to cellulose solutions in $\mathrm{LiCl} / \mathrm{DMAc}$ results in lower molecular weight cellulose and poor yields of reactions proceeding by nucleophilic substitution. ${ }^{6,7}$ In our experiments, a large excess of allyl bromide was used to react with the reactive cellulose alkoxide anion. The equivalent ratio of allyl bromide: alkoxide anion was $10: 1$, which was able to result in a high allyl DS and a good yield. The 2.80 allyl DS and above $80 \%$ of yield appeared reliable. Isogai et al. prepared benzyl cellulose by reacting benzyl chloride in cellulose- $\mathrm{LiCl} / \mathrm{DMAc}-\mathrm{NaOH}$ system, and reported a benzyl DS of 2.8 and a yield of $70 \% .^{9}$ The number-average molecular weight of allyl cellulose thus obtained was $2.74 \times 10^{4}$ from GPC (Table I). Kondo and co-workers reported an allylated

Table II. Analyses of Glycidyl DS and EEW for Glycidyl Cellulose by Titration

\begin{tabular}{ccccc}
\hline $\begin{array}{c}\text { Reaction } \\
\text { Time } \\
(\mathrm{h})\end{array}$ & $\begin{array}{c}\text { Sample } \\
\text { Weight } \\
(\mathrm{g})\end{array}$ & $\begin{array}{c}\text { Volume of } \\
\text { HCLO }_{4} \\
(\mathrm{~mL})\end{array}$ & $\begin{array}{c}\text { Glycidyl DS } \\
\text { per AHG }\end{array}$ & EEW \\
\hline 19 & 0.100 & 3.75 & 1.15 & 254.7 \\
24 & 0.100 & 3.93 & 1.21 & 243.0 \\
30 & 0.100 & 4.66 & 1.45 & 205.0 \\
42 & 0.100 & 5.77 & 1.83 & 165.5 \\
48 & 0.100 & 6.36 & 2.04 & 150.2 \\
72 & 0.100 & 6.76 & 2.19 & 141.3 \\
96 & 0.100 & 7.13 & 2.32 & 134.0 \\
120 & 0.100 & 7.35 & 2.41 & 130.0 \\
144 & 0.100 & 7.82 & 2.58 & 122.1 \\
\hline
\end{tabular}


Table III. Conversion of Epoxidation by ${ }^{1} \mathrm{H}-\mathrm{NMR}$ Integration

\begin{tabular}{rcccc}
\hline Time (h) & $\begin{array}{c}\text { Area of } \\
\mathbf{H}_{a}\end{array}$ & $\begin{array}{c}\text { Area of } \\
\mathbf{H}_{b}\end{array}$ & $\begin{array}{c}\text { Area of } \\
\mathrm{H}_{a}^{\prime}+\mathbf{H}_{b}^{\prime}\end{array}$ & $\begin{array}{c}\text { Percentage of }\left(\mathbf{H}_{a}^{\prime}+\mathbf{H}_{b}^{\prime}\right) / \\
\left(\mathbf{H}_{a}+\mathrm{H}_{b}+\mathbf{H}_{a}^{\prime}+\mathbf{H}_{b}^{\prime}\right)\end{array}$ \\
\hline 19 & 5.9 & 11.7 & 15.4 & 46.97 \\
24 & 6.4 & 12.5 & 23.1 & 55.00 \\
30 & 6.9 & 13.2 & 31.7 & 61.20 \\
42 & 7.4 & 13.6 & 53.0 & 71.93 \\
48 & 3.5 & 6.4 & 26.4 & 72.93 \\
72 & 1.6 & 3.0 & 23.5 & 83.63 \\
96 & 1.1 & 2.2 & 22.0 & 86.96 \\
120 & 0.6 & 1.2 & 15.7 & 89.70 \\
\hline
\end{tabular}

cellulose by reacting methyl cellulose with allyl chloride in DMSO. ${ }^{10}$ They reported an allyl DS of 1.6 by elemental analyses. Reactions involved in allylation and epoxidation in this study are shown below:
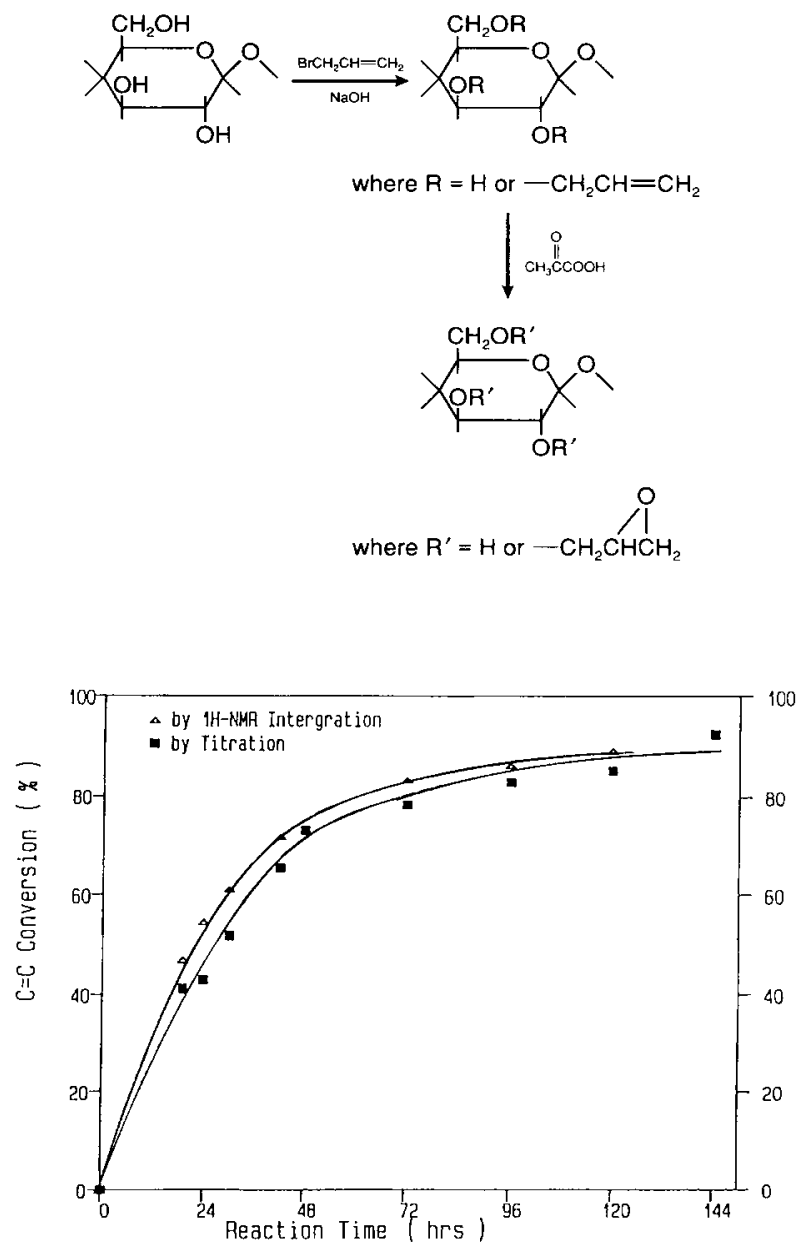

Figure 9. Conversions of $\mathrm{C}=\mathrm{C}$ bonds during epoxidation of allyl cellulose: $(\triangle)$ by ${ }^{1} \mathrm{H}-\mathrm{NMR}$ integration, ( by titration.
Figure 1 shows the FTIR spectrum of the prepared allyl cellulose. The residual $\mathrm{OH}$ groups showed its stretching vibration at around $3400 \mathrm{~cm}^{-1}$. Absorption of $\mathrm{C}=\mathrm{C}$ bond in allyl moiety was found at $1647 \mathrm{~cm}^{-1}$. Figure 2 shows its ${ }^{13} \mathrm{C}-\mathrm{NMR}$ spectrum, where the two vinyl carbons occurred at 136.6 (Ca) and $117.9 \mathrm{ppm}(\mathrm{C}-\mathrm{b})$, while the allylic carbon (C-n) occurred at $75.5 \mathrm{ppm}$. Peaks at 104.2, 82.9, $76.4,84.5,73.4$, and $69.3 \mathrm{ppm}$ were assigned to $\mathrm{C}-1$, C-2, C-3, C-4, C-5 and C-6, respectively. ${ }^{10}$ The ${ }^{1} \mathrm{H}-$ NMR spectrum of allyl cellulose is shown in Figure 3 , where the vinyl hydrogen $\mathrm{H}_{a}$ had chemical shift at 6.8 to $7.0 \mathrm{ppm}$ and, $\mathrm{H}_{b}$ at 6.0 to $6.3 \mathrm{ppm}$. The ratio of integration $\mathrm{H}_{a}: \mathrm{H}_{b}$ was $1: 2$ as would be expected. Allyl cellulose was soluble in organic solvents such as methylene chloride, chloroform, THF, dioxane, etc. Its TGA thermograms (Fig. 4) indicated an onset of decomposition at $250^{\circ} \mathrm{C}$ and a residual solvent content.

When this allyl cellulose with an allyl DS of 2.80 was dissolved in methylene chloride and treated with peracetic acid at ambient temperature for 6 days, a

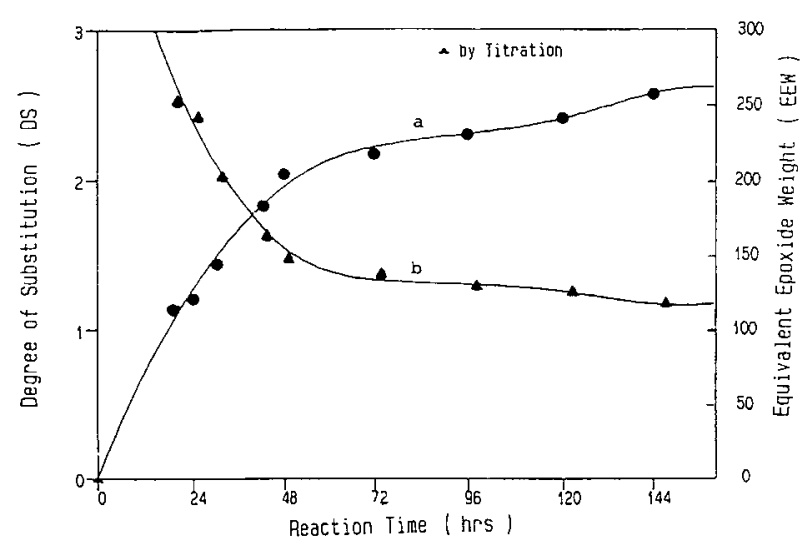

Figure 10. Plots of (a) glycidyl DS, and (b) epoxide equivalent weight versus reaction time. 
glycidyl cellulose with a glycidyl DS of 2.58 and a yield of $95.7 \%$ was obtained. Figure 5 shows its FTIR spectrum. The absorption of epoxide groups occurred at $911 \mathrm{~cm}^{-1}$, while the absorption of $\mathrm{C}=\mathrm{C}$ bonds at $1647 \mathrm{~cm}^{-1}$ disappeared. The ${ }^{13} \mathrm{C}-\mathrm{NMR}$ spectrum of the glycidyl cellulose in $\mathrm{CDCl}_{3}$ is shown in Figure 6, where the epoxide carbons had chemical shifts at $52.1 \mathrm{ppm}(\mathrm{C}-\mathrm{a})$ and $45.5 \mathrm{ppm}$ (C-b), respectively. The carbon next to epoxide (C-n) had chemical shift at $72.4 \mathrm{ppm}$. Figure 7 shows its ${ }^{1} \mathrm{H}$ NMR spectrum. The epoxide hydrogen $\mathrm{H}_{a}^{\prime}$ occurred at $2.75-2.85 \mathrm{ppm}$, and $\mathrm{H}_{b}^{\prime}$ occurred at $2.48-2.70 \mathrm{ppm}$. During epoxidation, the absorption of the allyl group decreased with increasing of epoxide concentration. Figure 8 shows a typical ${ }^{13} \mathrm{C}-\mathrm{NMR}$ spectrum of a partially epoxidized allyl cellulose in $\mathrm{CDCl}_{3}$ after 24 $\mathrm{h}$ of reaction. It was found that both allyl and epoxide groups were present. Conversion of epoxide was detected by titrating epoxide with perchloric acid and tetrabutylammonium iodide. ${ }^{11}$ The reaction can be expressed as follows:

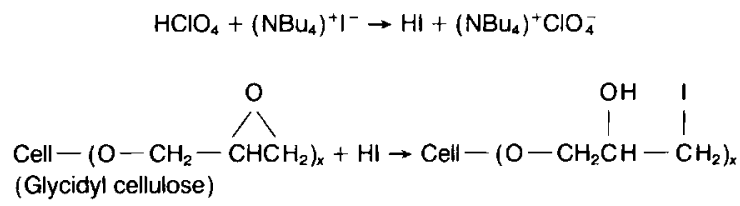

Data of titration are given in Table II. Analyses of conversions were also done with ${ }^{1} \mathrm{H}-\mathrm{NMR}$ integration. As mentioned previously, chemical shifts of the vinyl hydrogens in allyl cellulose $\left(\mathrm{H}_{a}, 6.8-7.0\right.$ ppm; $\mathrm{H}_{b}, 6.0-6.3 \mathrm{ppm}$ ) and the epoxide hydrogen in glycidyl cellulose $\left(\mathrm{H}_{a}^{\prime}, 2.75-2.85 \mathrm{ppm} ; \mathrm{H}_{b}^{\prime}, 2.48-2.70\right.$ ppm) were well known. The conversion of epoxi-

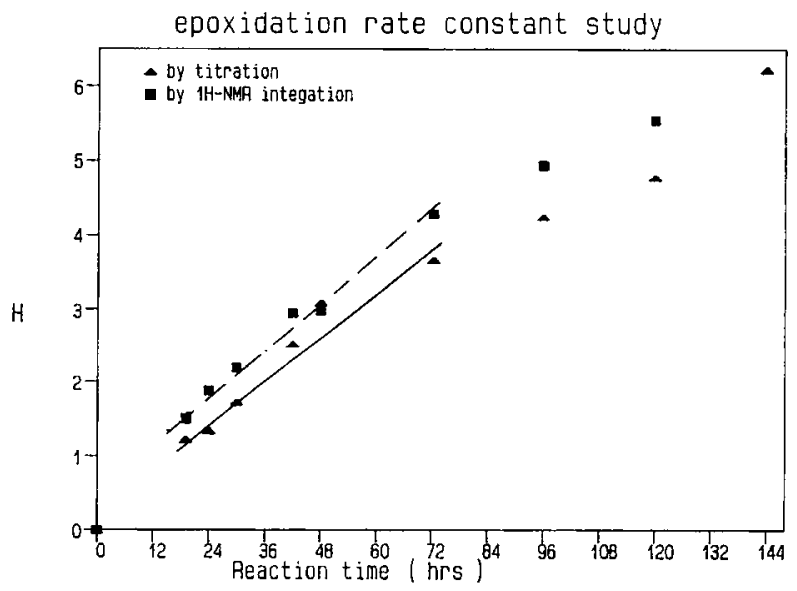

Figure 11. Plot of $\mathrm{H}$ versus reaction time according to eq. (5).

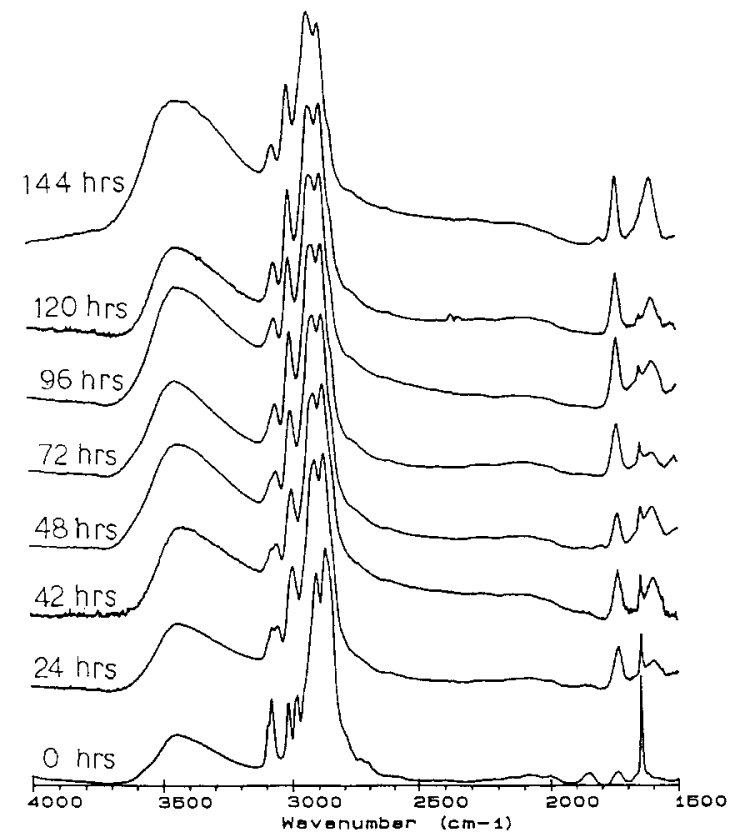

Figure 12. FTIR spectra of epoxidized products at var ious reaction time.

dation was calculated from the integration ratio of $\left(\mathrm{H}_{a}^{\prime}+\mathrm{H}_{\mathrm{b}}^{\prime}\right) /\left(\mathrm{H}_{a}+\mathrm{H}_{b}+\mathrm{H}_{a}^{\prime}+\mathrm{H}_{b}^{\prime}\right)$, and was summarized in Table III. Comparative results from titration and from ${ }^{1} \mathrm{H}$-NMR integration are illustrated in Figure 9. Both methods were agreeable.

Figure 10 shows the plots of glycidyl DS and EEW as functions of reaction time. A second order of reaction [eq. (4)] was established during epoxidation of allyl cellulose:

$$
-\frac{d[\mathrm{C}=\mathrm{C}]}{d t}=\frac{d[\mathrm{Q}]}{d t}=\frac{d x}{d t}=k(A-x)(B-x)
$$

where $A$ is the initial concentration of $\mathrm{C}=\mathrm{C}$ bond and $B$ is that of peracetic acid, $x$ is the concentration of epoxide group at time $t, k$ is rate constant. Integration of eq. (4) gives

$$
\mathrm{H}=\frac{2.303}{B-A} \log \frac{\mathrm{A}(B-x)}{B(A-x)}=k t
$$

Plot of $\mathrm{H}$ vs. $t$ gave a straight line up to $70 \%$ conversion, as is shown in Figure 11. The rate constant, $k$, obtained from the slope of the straight line was $1.33 \times 10^{-3} \mathrm{~min}^{-1}$.

Surprisingly, the starting material (allyl cellulose) had an allyl DS of 2.80 , compared with a glycidyl DS of 2.58 for the epoxidation product. The difference in DS (2.80-2.58) was probably due to 


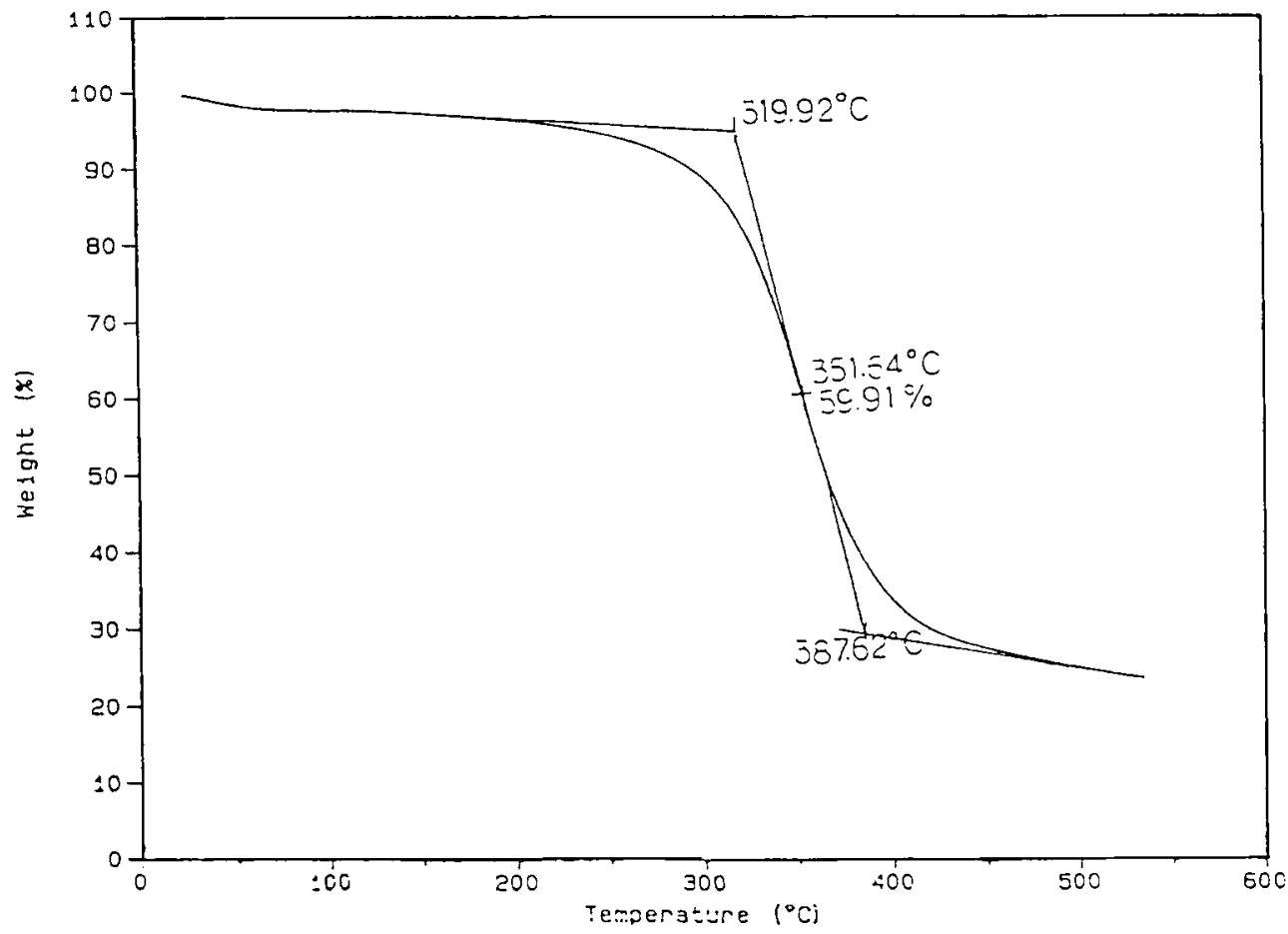

Figure 13. TGA thermogram of glycidyl cellulose.

the formation of ester group. This assumption was evidenced from successive product analyses by FTIR. Figure 12 shows the FTIR spectra of epoxidation products at various reaction times. It was found that a carbonyl peak occurred at $1735 \mathrm{~cm}^{-1}$, which was probably due to a side reaction of ring opening, leading to the formation of ester group as shown below:

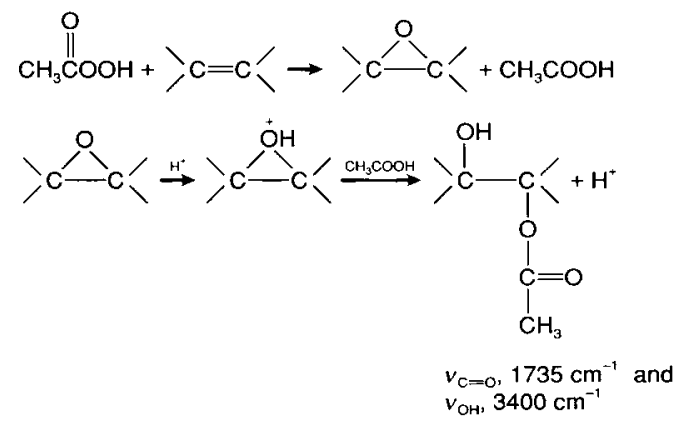

Continuous increase of the absorbances of $\mathrm{OH}$ at $3400 \mathrm{~cm}^{-1}$ and $\mathrm{C}=\mathrm{O}$ at $1735 \mathrm{~cm}^{-1}$ were observed simultaneously in the spectra. Udipi reported similar side reaction as he epoxidized SBS with performic acid. ${ }^{12}$ Glycidyl cellulose was soluble in organic sol- vents, such as chloroform, methylene chloride, acetone, THF, DMSO, etc. Its TGA thermograms is given in Figure 13. An onset of decomposition at around $210^{\circ} \mathrm{C}$ and a residual solvent content were observed from TGA. Gel permeation chromatograms of allyl cellulose and glycidyl cellulose are shown in

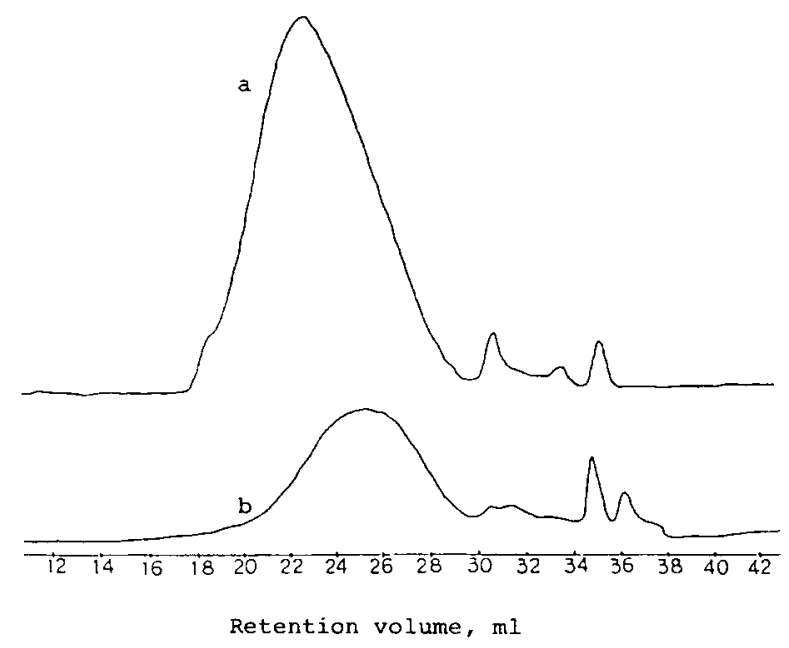

Figure 14. Gel permeation chromatograms of (a) allyl cellulose and (b) glycidyl cellulose. 
Figures 14(a) and 14 (b). Bimodal distribution and decreased molecular weight were found in the case of glycidyl cellulose (Table I), presumably because, during epoxidation in acidic medium, a small portions of chain scissions might have occurred at the cellulosic ether linkage of main chains.

\section{CONCLUSIONS}

Addition of $\mathrm{NaOH}$ powder in cellulose solution of $\mathrm{LiCl} / \mathrm{DMAc}$ resulted in the more reactive cellulose alkoxide anion. A high DS of 2.80 for allyl substitution and a reasonable yield could be achieved when the cellulose alkoxide reacted with a large excess of allyl bromide.

Epoxidation of this allyl cellulose in chloroform with peracetic acid also resulted in a high DS and a high yield of glycidyl cellulose. It was found from successive monitoring of FTIR that a minor portions of epoxide groups underwent ring opening leading to ester formation. Possible chain scission in cellulosic ether linkage was evidenced from GPC data.

The authors would like to express their sincere appreciation to National Science Council of R OC for financial support to this work under Contract Number NSC 800405-E009-06.

\section{REFERENCES AND NOTES}

1. T. R. Dawsey and C. L. McCormick, J. Macromol. Sci. Rev. Macromol. Chem. Phys., C30 (3\&4), 405440 (1990).

2. C. L. McCormick and D. K. Lichatowich, J. Polym. Sci. Polym. Lett. Ed., 17, 479-484 (1979).

3. C. L. McCormick, U.S. Pat. 4,278,790 (1981).

4. C. L. McCormick, D. K. Lichatowich, J. A. Pelezo, and K. W. Anderson, Polym. Prepr., 21, 109 (1980).

5. S. M. Hudson and J. A. Cuculo, J. Macromol. Sci. Rev. Macromol. Chem., C18(1), 1-82 (1980); 2981 (1986).

6. C. L. McCormick and P. A. Callais, Polymer, 28, 2317-2323 (1987).

7. C. L. McCormick and T. R. Dawsey, Macromolecules, 23, 3606-3610 (1990).

8. S. I. Takahashi, T. Fujimoyo, B. M. Barua, T. Miyamoto, and H. Inagaki, J. Polym. Sci. Polym. Chem. Ed., 24, 2981 (1986).

9. A. Isogai, A. Ishizu, and J. Nakano, J. Appl. Polym. Sci., 29, 2097-2109 (1984).

10. T. Kondo, A. Isogai, A. Ishizu, and J. Nankano, $J$. Appl. Polym. Sci., 34, 55-63 (1987).

11. J. H. Yang, Ph.D. dissertation, National Tsing Hua University, Taiwan, June, 1990, pp. 136-137.

12. K. Udipi, J. Appl. Polym. Sci., 23,3301-3309 (1979).

Received August 12, 1991

Accepted November 24, 1991 